\title{
Análisis de los tratados internacionales para el reconocimiento del derecho de sufragio local a personas extranjeras residentes en España que no ostentan la ciudadanía europea
}

\section{An analysis of international treaties for the recognition of the right of local suffrage to foreign residents in Spain who do not hold European citizenship}

\author{
Carlos Arce Jiménez \\ Universidad de Córdoba (España) \\ ORCID: https://orcid.org/0000-0001-8920-6440 \\ carce@uco.es
}

\section{NOTA BIOGRÁFICA}

Doctor en Derecho por la UCO. Profesor dr. del Área de Derecho Constitucional de la UCO. Profesor de posgrado en CLACSO (Consejo Latinoamericano de Ciencias Sociales) y la Universidad Centroamericana «José Simeón Cañas» (El Salvador). Coordinador del Área de migraciones de la Asociación Pro Derechos Humanos de Andalucía. Líneas de investigación: ciudadanía, Derechos Humanos, participación política y migraciones.

\section{RESUMEN}

Habiendo transcurrido cerca de una década del inicio, en el marco del art. 13.2 CE, del segundo proceso de suscripción de tratados bilaterales para el reconocimiento del derecho de sufragio local a personas extranjeras residentes en España de algunas nacionalidades, es un buen momento para realizar un balance respecto a la incidencia práctica de los mismos. Tras haber desplegado sus efectos en dos convocatorias electorales (municipales de 2011 y 2015), y a las puertas de los comicios locales de 2019, el nivel de participación de los potenciales beneficiarios de los tratados ha sido muy escaso. En este artículo se analizan críticamente estos instrumentos internacionales, ofreciendo alternativas para avanzar realmente en los derechos de participación política de los residentes extranjeros.

\section{PALABRAS CLAVE}

Ciudadanía; criterio de reciprocidad; derecho de sufragio local; residentes extranjeros; tratado internacional.

\begin{abstract}
Nearly a decade after the beginning of the second signing process of bilateral treaties to the recognition of the right to suffrage at the local level to foreign residents in Spain of some nationalities, within the framework of article 13.2 of Spanish Constitution, it's time to make a balance regarding the practical incidence of that process. After having developed its effects in two electoral calls (municipal elections of 2011 and 2015), and at the gates of the local elections of 2019, the level of participation of potential beneficiaries of the treaties has been very low. This article analyses from a critical point of view these international instruments, offering alternatives to really advance in the recognition of the rights of political participation of foreign residents.
\end{abstract}

\section{KEYWORDS}

Citizenship; reciprocity criterion; right to suffrage at the local level; foreign residents; international treaty. 
REALA. Nueva Época - N.o 11, Abril-Septiembre 2019 - ISSN: 1989-8975 - DOI: 10.24965/reala.v0i11.10591 - [Págs. 139-155]

Análisis de los tratados internacionales para el reconocimiento del derecho de sufragio local a personas extranjeras residentes..

Carlos Arce Jiménez

\begin{abstract}
SUMARIO
INTRODUCCIÓN. 1. MARCO JURÍDICO CONSTITUCIONAL DEL DERECHO DE SUFRAGIO DE LAS PERSONAS EXTRANJERAS EN ESPAÑA. 2. LOS PRIMEROS ANTECEDENTES DEL RECONOCIMIENTO CONVENCIONAL: LOS TRATADOS DE LOS AÑOS OCHENTA Y NOVENTA. 2.1. TRATADOS CON PAÍSES EUROPEOS. 2.2. TRATADOS CON PAÍSES DE AMÉRICA LATINA. 3. EL NUEVO PROCESO DE SUSCRIPCIÓN DE TRATADOS INTERNACIONALES BAJO EL CRITERIO DE RECIPROCIDAD. 4. VALORACIÓN DE LA INCIDENCIA PRÁCTICA DE LOS NUEVOS TRATADOS EN EL AVANCE DEL RECONOCIMIENTO DEL DERECHO DE SUFRAGIO MUNICIPAL DE LOS RESIDENTES EXTRANJEROS. CONCLUSIONES: PROPUESTAS DE MEDIDAS POLÍTICO-JURÍDICAS PARA AVANZAR EN LA UNIVERSALIZACIÓN DEL DERECHO DE SUFRAGIO A NIVEL LOCAL. 1. POSIBLES REFORMAS DENTRO DEL MARCO CONSTITUCIONAL VIGENTE (RESPETANDO LA EXIGENCIA DE RECIPROCIDAD). 2. REFORMAS QUE SUPERAN EL MARCO CONSTITUCIONAL VIGENTE. REFERENCIAS BIBLIOGRÁFICAS.
\end{abstract}

\title{
INTRODUCCIÓN
}

Los flujos migratorios contemporáneos han cambiado la configuración social, política y jurídica global. Según la División de Población del Departamento de Asuntos Económicos y Sociales de la ONU, en el periodo 2000-2015 las migraciones internacionales ascendieron a 71 millones de personas (ONU, 2016). Evidentemente esta intensa movilidad humana transforma tanto a los países de origen como a los de acogida, planteando importantes retos en esa triple dimensión social, política y jurídica.

El principal destino de esas migraciones internacionales son los países de altos ingresos ${ }^{1}$, situados mayoritariamente en el mundo occidental, con 57 millones de entradas en ese periodo, el $81 \%$ del total (ONU, 2016). Estos Estados afrontan el reto de buscar un encaje adecuado de las personas inmigrantes en sus sistemas de titularidad y ejercicio de los derechos fundamentales.

A un nivel internacional se han intentado habilitar herramientas para dar respuesta a este nuevo contexto. Desde una perspectiva global (material y geográfica), podemos destacar la Convención ONU sobre la protección de los derechos de todos los trabajadores migratorios y de sus familiares (1990), que trata de garantizar un estatuto mínimo de derechos a las personas migrantes tanto en sus países de origen como en los de destino. Llama la atención por una parte que la propia denominación del tratado se centra en el aspecto laboral de las migraciones (aunque en el contenido sustantivo se regulan cuestiones más allá de esa perspectiva), y el hecho de que no haya sido ratificado por ninguno de los principales receptores de flujos migratorios, por otra.

En el marco regional europeo, y fijando nuestra atención en la materia que nos ocupa en este artículo, es reseñable el Convenio europeo sobre la participación de los extranjeros en la vida pública local (1992), del Consejo de Europa. Este instrumento supera la cerrada identificación entre persona migrante y trabajadora, y avanza en el reconocimiento de la ciudadanía de los residentes extranjeros, especialmente en su aspecto activo, que se expresa fundamentalmente a través de la participación política. Sin embargo, el alcance del convenio es muy limitado, tanto por su contenido material como por las escasas ratificaciones de las que ha sido objeto.

Ya en la Unión Europea, el concepto de ciudadanía europea ha supuesto un significativo impulso en la superación del estricto vínculo entre ciudadanía, los derechos de participación política y la condición de nacional. Se reconoce a todos los ciudadanos europeos, independientemente del país de residencia, el sufragio activo y pasivo en las elecciones al Parlamento Europeo y en las municipales en el Estado que residan en igualdad de condiciones que los nacionales del mismo (arts. 20.2.b y 22 TFUE). Sin embargo, no se puede afirmar que haya supuesto una desconexión absoluta entre ciudadanía y nacionalidad, ya que para acceder a la ciudadanía europea es imprescindible ostentar la condición nacional de uno de los Estados miembro (Arce 2015: 72). A lo anterior se une que los residentes de terceros países tienen vedado el acceso a los derechos políticos vinculados a esta institución ${ }^{2}$.

\footnotetext{
1 Se considera que un país es de ingresos altos cuando su ingreso nacional bruto (INB) es igual o superior a los 11.906 US\$. Países de ingresos bajos serían aquellos cuyo INB es inferior a los 995 US $\$$, los países de ingresos medianos altos tienen un INB entre 3.896 US \$ y 12.055 US\$ y en los de ingresos medianos bajos el INB se sitúa entre 976 US\$ y 3.855 US\$). Banco Mundial: $h t t p s: / / b l o g s$. worldbank.org/opendata/es/nueva-clasificacion-de-los-paises-segun-el-nivel-de-ingreso-para-el-periodo-2018-19 (23-01-2019).

2 Hay que destacar que dos sentencias del Tribunal de Justicia de la Unión Europea de 12-09-2006 (caso C-145/04 -Reino de España vs Reino Unido de Gran Bretaña e Irlanda del Norte- y caso C-300/04 -M. G. Eman y O. B. Servinger vs College van bur-
} 
REALA. Nueva Época - N.o 11, Abril-Septiembre 2019 - ISSN: 1989-8975 - DOI: 10.24965/reala.v0i11.10591 - [Págs. 139-155]

Análisis de los tratados internacionales para el reconocimiento del derecho de sufragio local a personas extranjeras residentes..

Carlos Arce Jiménez

Además de estas iniciativas a nivel internacional, en el Derecho comparado estatal encontramos diferentes realidades normativas sobre el binomio «ciudadanía-participación política» en lo que a las personas residentes extranjeras se refiere. No siendo el lugar adecuado para realizar un análisis detallado de este aspecto, baste con indicar que, aunque se mantienen fuertes resistencias para desvincular de una manera definitiva la ciudadanía de la nacionalidad, sí que hay avances relevantes en el reconocimiento de los derechos de participación política de los residentes extranjeros, especialmente en el ámbito local.

\section{MARCO JURÍDICO-CONSTITUCIONAL DEL DERECHO DE SUFRAGIO DE LAS PERSONAS EXTRANJERAS EN ESPAÑA}

Una vez expuesto un somero contexto global, es ineludible a los efectos que nos interesan hacer una breve referencia al marco constitucional de reconocimiento del derecho de sufragio de las personas extranjeras residentes en España. Los arts. 13.2 y 23 del texto constitucional como norma general reservan el derecho de sufragio a los nacionales españoles, estableciendo el art. 13.2 una excepción: lo que, atendiendo a criterios de reciprocidad, pueda establecerse por tratados o ley para el derecho de sufragio activo y pasivo en las elecciones municipales.

El citado precepto fue objeto de reforma en el año 1992 para adaptarlo a las exigencias de la ciudadanía europea. En su redacción original el art. 13.2 CE solo establecía la posibilidad de reconocer el sufragio activo local de personas extranjeras, por lo que tuvo que ser modificado para introducir el pasivo, al que también tienen derecho los ciudadanos europeos desde el Tratado de Maastricht. De forma previa a esta reforma se pronunció el Tribunal Constitucional a través de la Declaración 1/1992, donde consideró que la apertura del sufragio pasivo municipal a las personas extranjeras era constitucional debido a que no incidía sobre el principio de soberanía popular (art. 1.2 CE) . $^{3}$

El art. 13.2 CE permite materializar el reconocimiento del derecho de sufragio local a las personas residentes extranjeras por vía convencional o por vía legal, respetando siempre el criterio de reciprocidad. El legislador hasta el momento ha optado de forma exclusiva por la opción del tratado bilateral (con la excepción del Tratado de Maastricht, aprobado en el contexto multilateral de la Unión Europea). Simplemente destacar por ahora que coincidimos con Naranjo respecto a que la vía convencional presenta graves limitaciones si se sostiene una perspectiva pro-derechos en esta materia. Por una parte, el reconocimiento del derecho de voto activo y pasivo de los residentes extranjeros en el ámbito local queda supeditado en gran medida a los intereses de política exterior del Estado español, y por otra la propia mecánica jurídica del tratado internacional hace difícil ofrecer una solución homogénea a nacionales de diferentes Estados (Naranjo 2017: 98).

Lo anterior no obsta para que ese reconocimiento convencional tenga su reflejo en el ordenamiento jurídico interno español, con el objetivo de establecer las herramientas normativas y administrativas vinculadas al ejercicio de derecho de sufragio de los residentes extranjeros en España. De esta manera los arts. 176 y 177 LO 5/1985 (LOREG) regulan la materia en las elecciones locales y los arts. 210 y 210 bis LO 5/1985 (LOREG) en las europeas ${ }^{4}$. Junto a lo dispuesto en la LO 5/1985 (LOREG), tiene una gran incidencia en el ejercicio práctico de los derechos políticos de los residentes extranjeros la configuración del Censo Electoral de los Residentes Extranjeros (CERE), debido a que a diferencia de lo que ocurre con los nacionales españoles, la incorporación al mismo no es automática desde el padrón municipal de habitantes, sino que es a instancia de parte (el conocido como «voto rogado»).

Partiendo del marco constitucional descrito, y del desarrollo convencional del reconocimiento del derecho de sufragio local de los residentes extranjeros que es objeto de este artículo, concluimos el apartado con este cuadro-resumen sobre el panorama de la titularidad de los derechos políticos de democracia representativa en España:

\footnotetext{
gemeester en wethouders van Den Haag-) abrieron con limitaciones la posibilidad de que los nacionales de terceros países puedan participar en las elecciones europeas en algunos supuestos concretos.

3 Posicionamiento refrendado por el Consejo de Estado en su informe sobre propuestas de modificación del régimen electoral general, de 24 de febrero de 2009 (pág. 62).

${ }^{4}$ En el caso de los ciudadanos europeos, habrá que tener en cuenta también los arts. 39 y 40 CDFUE, arts. 20 y 22 TFUE y las directivas 93/109/CE y 94/80/CE.
} 
REALA. Nueva Época - N.o 11, Abril-Septiembre 2019 - ISSN: 1989-8975 - DOI: 10.24965/reala.v0i11.10591 - [Págs. 139-155]

Análisis de los tratados internacionales para el reconocimiento del derecho de sufragio local a personas extranjeras residentes..

Carlos Arce Jiménez

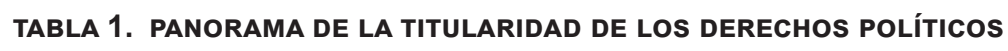
DE DEMOCRACIA REPRESENTATIVA EN ESPAÑA

\begin{tabular}{|c|c|}
\hline Tipo de titular & Nivel de reconocimiento de derechos políticos \\
\hline Nacionales españoles & $\begin{array}{l}\text { Sufragio activo y pasivo en todo tipo de elecciones (locales, autonómicas, } \\
\text { nacionales y europeas), salvo las restricciones legalmente establecidas por } \\
\text { edad, incapacidad, incompatibilidad, residencia en el exterior o condena penal. } \\
\text { Arts. } 13 \text { y } 23 \text { CE y arts. } 2 \text { a } 7 \text { LO } 5 / 1985 \text { (LOREG), esencialmente, además } \\
\text { de lo dispuesto en los correspondientes Estatutos de Autonomía y normativa } \\
\text { de desarrollo para las elecciones autonómicas y lo reseñado en el apartado } \\
\text { siguiente para las europeas. }\end{array}$ \\
\hline $\begin{array}{l}\text { Ciudadanos europeos } \\
\text { residentes en España }\end{array}$ & $\begin{array}{l}\text { Sufragio activo y pasivo en elecciones locales y europeas, con las restricciones } \\
\text { establecidas por la normativa UE. Arts. } 39 \text { y } 40 \text { CDFUE, arts. } 20 \text { y } 22 \text { TFUE, } \\
\text { directivas 93/109/CE y 94/80/CE y arts. } 176,177,210 \text { y ss LO 5/1985 (LOREG). }\end{array}$ \\
\hline $\begin{array}{l}\text { Residentes extranjeros no UE } \\
\text { cuyo país tenga tratado con } \\
\text { España en materia de sufragio } \\
\text { local }\end{array}$ & $\begin{array}{l}\text { Sufragio activo en las elecciones locales, con las restricciones establecidas por } \\
\text { la normativa electoral española y con los requisitos previstos en los tratados. Art. } \\
13.2 \mathrm{CE} \text {, tratados de España en materia de sufragio local con Bolivia, Cabo Verde, } \\
\text { Chile, Colombia, Corea del Sur, Ecuador, Islandia, Paraguay, Perú, Noruega, } \\
\text { Nueva Zelanda y Trinidad y Tobago y arts. } 176 \text { y } 177 \text { LO 5/1985 (LOREG). }\end{array}$ \\
\hline
\end{tabular}

Residentes extranjeros no UE cuyo país no tenga tratado con España en materia de sufragio local y personas extranjeras en situación documental irregular

Fuente: Elaboración propia.

\section{LOS PRIMEROS ANTECEDENTES DEL RECONOCIMIENTO CONVENCIONAL: LOS TRATADOS DE LOS AÑOS OCHENTA Y NOVENTA}

El proceso de reconocimiento convencional del derecho de sufragio local de las personas extranjeras residentes tuvo una primera etapa en los años 80 y 90 . Se firmaron tratados con 4 países europeos y con 5 de América Latina. Cada uno de estos grupos de instrumentos internacionales tuvo unas características formales y materiales diferentes, por lo que los analizaremos de forma separada.

\subsection{Tratados con países europeos}

Se formalizaron tratados con Holanda, Dinamarca, Suecia y Noruega ${ }^{5}$. Estos instrumentos adoptaron la forma de «canje de notas/cartas», que es el tipo de acuerdo internacional que requiere un menor nivel de requisitos formales. Esta circunstancia conllevó algún debate doctrinal, aunque el Consejo de Estado ha considerado dicha forma como adecuada para convenios internacionales que traten sobre esta materia en diversos pronunciamientos ${ }^{6}$. En este sentido, también es pertinente señalar que el art. 2.1 del Convenio de

${ }^{5}$ Canje de Cartas y Anejos, constitutivo de Acuerdo entre España y Países Bajos, realizado en Madrid el 23 de febrero de 1989, reconociendo el derecho a votar en elecciones municipales a los nacionales holandeses en España y a los españoles en Países Bajos (BOE 08-08-1990) / Intercambio de Cartas y Anejos, de 13 de julio de 1989, constitutivo de Acuerdo entre España y Dinamarca, reconociendo el derecho a votar en elecciones municipales a los nacionales daneses en España y a los españoles en Dinamarca (BOE 30-11-1990) / Canje de Cartas constitutivo de Acuerdo entre España y Suecia, reconociendo el derecho de sufragio activo en elecciones municipales a los nacionales suecos en España y a los españoles en Suecia, realizado en Madrid el 6 de febrero de 1990 (BOE 27-061991) / Canje de Cartas constitutivo de Acuerdo entre España y Noruega, reconociendo el derecho de sufragio activo en elecciones municipales a los nacionales noruegos en España y a los españoles en Noruega, realizado en Madrid el 6 de febrero de 1990 (BOE 27-06-1991).

${ }^{6}$ Dictámenes 53.825 de 30 de noviembre -tratado con Dinamarca-; 54.685 -Noruega-y 54.686 -Suecia- de 8 junio 1989, 370 -Perú- y 414 -Argentina- de 02-04-2009. Afirma que a pesar de usar este instrumento internacional más «informal» es necesaria la previa autorización de las Cortes Generales antes de su entrada en vigor. 
Viena sobre el Derecho de los Tratados determina que prevalece el contenido sustantivo de un tratado sobre la denominación que se le asigne al mismo.

Los cuatro tratados establecen los mismos requisitos y alcance del reconocimiento del derecho de sufragio municipal: excluyen el sufragio pasivo, exigen la residencia legal en España de al menos de 3 años ininterrumpidos, el empadronamiento en el municipio donde se desee ejercer el derecho al voto y el alta en el censo electoral no se realiza de oficio a partir del padrón municipal, sino que se contempla el «voto rogado».

Cuando se formalizaron estos tratados (1989-1990) todavía no se había reformado el art. 13.2 CE, por lo que, aunque hubiera habido voluntad de reconocer el sufragio pasivo a los nacionales de estos países, no hubiera sido posible. El requisito de la reciprocidad sin embargo no hubiera representado un problema, ya que los ordenamientos jurídicos de los cuatro países permiten esta posibilidad desde hace décadas.

Hemos visto que estos tratados exigen una residencia legal mínima en España de 3 años. Ni siquiera la residencia legal en sí misma es una exigencia expresa del texto constitucional, por lo que el plazo mínimo requerido (en el caso de que se establezca alguno) quedaría a lo que atendiendo a criterios de reciprocidad, pueda establecerse por tratado o ley... (art. 13.2 CE). En el caso que nos ocupa, la justificación de que se establezca este plazo podría basarse en que Dinamarca, Noruega y Suecia exigen dicho periodo de residencia para el reconocimiento del derecho de sufragio municipal a los residentes extranjeros. No obstante, en Holanda es necesario un plazo de 5 años, por lo que el tratado que suscribió España con el Estado holandés establecía una «reciprocidad asimétrica», ya que las personas españolas residentes en Países Bajos tenían un requisito temporal más exigente que las holandesas residentes en territorio español a la hora de ejercer el derecho de sufragio en el ámbito local. Podría defenderse que la reciprocidad conlleva una identidad plena de las condiciones de ejercicio del derecho de sufragio entre los países que firmen tratados de esta naturaleza, pero el Consejo de Estado ha sostenido una interpretación más flexible que abre la puerta a la citada «reciprocidad asimétrica» ${ }^{7}$.

Concluir el presente apartado destacando que la virtualidad práctica de estos tratados fue escasa. Dinamarca y Holanda eran miembros de la Comunidad Europea en el momento de su ratificación, por lo que cuando en 1992 entró en vigor el Tratado de Maastricht ${ }^{8}$ sus nacionales devinieron en ciudadanos de la Unión Europea y por ende titulares de los derechos políticos vinculados a esta condición, quedando obsoletos desde ese mismo momento los canjes de cartas formalizados con España en 1989. El mismo razonamiento es aplicable a Suecia desde su adhesión a la UE en 1995. De esta manera, a día de hoy tan sólo se mantiene en vigor el suscrito con Noruega.

\subsection{Tratados con países de América Latina}

En el periodo 1988-1992 España firmó Tratados Generales de Cooperación y Amistad con Argentina, Venezuela, Chile, Uruguay y Colombia ${ }^{9}$.

Estos instrumentos internacionales se diferencian de sus contemporáneos con países europeos desde el punto de vista formal y desde el sustantivo. En el primer aspecto destacar que recibieron la denominación de «tratado», mucho más formal que el «canje de cartas/notas», aunque con las matizaciones derivadas del art. 2.1 del Convenio de Viena sobre el Derecho de los Tratados ya apuntadas. En el segundo poner de relieve que estos tratados establecían un marco general de colaboración entre España y sus contrapartes en materias económicas, políticas, culturales, científicas..., en el que como un elemento más se incluía la cuestión de los derechos políticos en el ámbito local.

Centrándonos en el objeto del presente artículo, los cinco tratados hacen referencia sólo al sufragio activo municipal. No podía ser de otra manera para España, como en el caso de los canjes de notas con los Estados europeos, debido a que fueron suscritos con anterioridad a la entrada en vigor de la reforma del art. 13.2 CE de 1992 (a excepción del celebrado con Colombia, que fue firmado dos meses después de la modificación constitucional). A mayor abundamiento, la realidad de los ordenamientos jurídicos de estos países

\footnotetext{
7 Ver en el señalado informe del Consejo de Estado sobre "Propuestas de modificación del régimen electoral general", de 24 de febrero de 2009 (pág. 72).

${ }^{8}$ El Tratado de Maastricht desde un punto de vista jurídico también cumple las funciones de instrumento internacional bajo el criterio de reciprocidad de reconocimiento mutuo del derecho de sufragio municipal entre los Estados miembro de la UE. A pesar de lo anterior, un análisis detallado del Tratado de Maastricht excede con mucho los objetivos del presente artículo.

9 Tratados generales de Cooperación y Amistad con Argentina (03-06-1988, BOE 28-08-1989), Venezuela (07-06-1990, BOE 1607-1992), Chile (22-08-1991, BOE 17-09-1991), Uruguay (23-07-1992, BOE 02-06-1994) y Colombia (29-10-1992, BOE 01-08-1995).
} 
REALA. Nueva Época - N.o 11, Abril-Septiembre 2019 - ISSN: 1989-8975 - DOI: 10.24965/reala.v0i11.10591 - [Págs. 139-155]

Análisis de los tratados internacionales para el reconocimiento del derecho de sufragio local a personas extranjeras residentes..

Carlos Arce Jiménez

latinoamericanos en ese momento igualmente excluía la posibilidad del sufragio pasivo local de extranjeros, a excepción de dos provincias de Argentina.

Los tratados no precisaron los requisitos de ejercicio del derecho de sufragio que recíprocamente se reconocían. De hecho, los suscritos con Argentina, Colombia, Uruguay y Venezuela se remitieron directamente a un futuro acuerdo complementario para concretar esos extremos. Sin embargo, el art. 17 del tratado con Chile disponía que:

Se concederá a los nacionales de ambos países el derecho de voto en las elecciones municipales del Estado en que residan y del que no sean nacionales, de conformidad con sus respectivas legislaciones.

Argentinos, colombianos, uruguayos y venezolanos no tuvieron la oportunidad de acceder al derecho de sufragio municipal a través de estos tratados debido a que nunca se llegaron a celebrar los acuerdos que debían fijar las condiciones de ejercicio. Tan sólo los colombianos han visto reconocido este derecho a través de un nuevo acuerdo internacional de 2010, que está totalmente desconectado del Tratado General de Cooperación y Amistad de 1992.

En el caso de Chile, algunas voces en la doctrina -Santolaya y Díaz (2008: 32-34) y Durán y Martín (2008: 143-144)- sugirieron en su momento que del tenor literal del art. 17 de su tratado («de conformidad con sus respectivas legislaciones») se desprendía que solo se requerían adaptaciones normativas de Derecho interno para el reconocimiento mutuo del derecho al voto municipal. Dado que el ordenamiento jurídico chileno ya permitía los españoles ( $y$ al resto de residentes extranjeros que cumplieran los requisitos establecidos) participar en sus elecciones municipales, consideran que los residentes chilenos en España podrían haber reclamado por vía administrativa y/o judicial que el Estado español cumplimentara las modificaciones legislativas pertinentes para que pudieran ejerecer su derecho al sufragio activo local. Sin embargo, este debate dejo de tener relevancia desde que Chile y España formalizaron en 2010 un nuevo instrumento internacional para el reconocimiento mutuo de la participación de sus respectivos nacionales en las elecciones municipales, sin ningún tipo de vinculación con el Tratado General de Cooperación y Amistad, como en el caso de Colombia.

\section{EL NUEVO PROCESO DE SUSCRIPCIÓN DE TRATADOS INTERNACIONALES BAJO EL CRITERIO DE RECIPROCIDAD}

Entre 2009 y 2011 el Estado español suscribió 11 nuevos instrumentos internacionales bilaterales bajo el criterio de reciprocidad para reconocer el derecho de sufragio local a los nacionales de otros tantos países residentes en España, con el correlativo reconocimiento para los españoles que viven en dichos Estados. Este proceso se produjo en un contexto en el que diversas propuestas parlamentarias en los años previos ${ }^{10}$, el citado informe del Consejo de Estado de 24 de febrero de 2009 y nuevos textos normativos como el Estatuto de la Ciudadanía Española en el Exterior (Ley 40/2006, de 14 de diciembre) ${ }^{11}$ abogaban por avanzar en esta línea.

El punto de partida formal de la iniciativa lo podemos localizar en un acuerdo del Consejo de Ministros de 16 de enero de 2009. En el mismo se daba cuenta de la firma de los primeros tratados con Colombia y Perú, pero también se anunciaba la intención del Gobierno de España de firmar instrumentos internacionales con otros 13 países más ${ }^{12}$. En una primera revisión de los resultados prácticos del proceso podemos destacar:

10 Proposición no de ley presentada por IU el 26-11-2002 (Boletín Oficial de las Cortes Generales 29-11-2002), proposición no de ley presentada por IU-ICV el 20-05-2004 (BOCG 24-05-2004), proposición no de ley presentada por IU-ICV el 21-02-2006 (BOCG 0203-2006), proposición no de ley presentada por PSOE e IU-ICV el 10-07-2006 (BOCG 11-09-2006) y proposición no de ley presentada por ERC e IU-ICV el 03-07-2008 (BOCG 18-07-2008), proposición de Ley Orgánica 122/000169 para el reconocimiento del derecho de sufragio activo y pasivo a los ciudadanos extranjeros en España. Presentada por el Grupo Parlamentario de Izquierda Verde / Izquierda Unida / Iniciativa per Catalunya Verds (BOCG 07-10-2005) y proposición de Ley Orgánica 122/000048 para el reconocimiento del derecho de sufragio activo y pasivo a los ciudadanos extranjeros en España Presentada por el Grupo Parlamentario de Esquerra Republicana / Izquierda Unida / Iniciativa per Catalunya Verds (BOCG 22-04-2008).

${ }^{11}$ El art. 4.2 de la Ley 40/2006 establece que El Estado fomentará los tratados internacionales oportunos para que los residentes españoles en el exterior vean reconocido el derecho a ser elector y elegible en las elecciones municipales de su lugar de residencia, bajo los criterios de reciprocidad que se establezcan en dichos tratados o en la ley.

12 Consejo de Ministros de 16 de enero de 2009. http://www.lamoncloa.gob.es/consejodeministros/referencias/Paginas/2009/ refc20090116.aspx\#EleccionesMunicipales (23-01-2019). 
REALA. Nueva Época - N. 11, Abril-Septiembre 2019 - ISSN: 1989-8975 - DOI: 10.24965/reala.v0i11.10591 - [Págs. 139-155]

Análisis de los tratados internacionales para el reconocimiento del derecho de sufragio local a personas extranjeras residentes..

Carlos Arce Jiménez

- 11 tratados firmados, autorizados en sede parlamentaria, publicados en el BOE y en vigor (con Bolivia, Cabo Verde, Chile, Colombia, Corea del Sur, Ecuador, Islandia, Paraguay, Perú, Nueva Zelanda y Trinidad y Tobago) ${ }^{13}$.

- 2 tratados firmados con Argentina y Uruguay, enviados por el Consejo de Ministros a las Cortes para su autorización, pero que no superaron la tramitación parlamentaria (terminaron caducando sendas iniciativas). Esta situación se produjo porque se consideró en el debate en el Congreso que ambos acuerdos internacionales presentaban serias dificultades para su aprobación por diferentes motivos. En el caso de Argentina, porque el reconocimiento del derecho de sufragio local de los residentes extranjeros es competencia provincial, no estatal, lo que determina la existencia de una pluralidad de regulaciones en la República argentina que impediría ofrecer una «reciprocidad homogénea» a los residentes españoles en ese país. Uruguay por su parte exige a los residentes extranjeros unos requisitos excesivos en cuanto al tiempo mínimo de residencia (15 años) y otros que podrían calificarse casi de extravagantes o extemporáneos (estar casado con un nacional uruguayo o ser "propietario»), lo que se consideró que superaba la flexibilidad admisible respecto al criterio de reciprocidad ${ }^{14}$.

- En Consejo de Ministros ${ }^{15}$ se autorizó la firma del correspondiente canje de notas con Burkina Faso, pero nunca llegó a ser remitido a las Cortes. Respecto a Venezuela, tras la primera declaración de intenciones de inicios de 2009 , no se tiene constancia de ningún avance conducente a la posible formalización de un tratado bilateral con España en esta materia.

Ante el panorama descrito, se puede afirmar que esta nueva generación de tratados es diferente a la de los años ochenta y noventa. Es innegable que en ella reside una voluntad más firme de realizar avances sustantivos en el reconocimiento de los derechos políticos de los residentes extranjeros en España a nivel municipal, tanto por el número y diversidad de los países incluidos en el proceso como por el hecho de que la mayoría de los instrumentos suscritos ya estén en vigor (salvo las excepciones señaladas de Argentina, Burkina Faso, Uruguay y Venezuela). A pesar de lo anterior, a nuestro juicio la vía de los tratados bilaterales bajo el criterio de reciprocidad no es la adecuada si se pretende conseguir una universalización de la participación política local de los residentes extranjeros, por cuestiones formales y materiales sobre las que reflexionaremos más adelante.

Tal como ocurrió con los instrumentos suscritos con países europeos entre los años 89 y 91, los nuevos tratados adoptan la forma de "canje de notas» ${ }^{16}$. Damos por reproducidos aquí los comentarios que hicimos al respecto en el apartado correspondiente. Las condiciones de ejercicio del derecho de sufragio municipal en España son comunes en todos los nuevos tratados:

- Se excluye el sufragio pasivo.

- Residencia legal en España de al menos 5 años.

- Inscripción en el Padrón del municipio donde se desee ejercer el derecho de voto municipal.

- «Voto rogado» (inscripción en el censo electoral a instancia de parte). A este respecto todos los tratados indican que «el plazo de presentación se fijará para cada elección municipal». De ello parece inferirse que los residentes extranjeros a los que se les reconoce el derecho de sufragio local deben inscribirse en el censo electoral en cada uno de los comicios, sin que se entienda que su voluntad de participar se mantiene si no se manifiesta lo contrario.

Es posible valorar estos tratados desde diferentes perspectivas. Por una parte, se podría poner de relieve que existe cierta arbitrariedad en la elección de los países con los que se han suscrito. Quizás sería plausible alegar razones históricas para la preponderancia de países latinoamericanos entre ellos, pero es difícil hallar la razón que justifica priorizar a Estados como Cabo Verde, Corea del Sur, Nueva Zelanda o

${ }^{13}$ Ecuador (BOE 05-01-2010), Colombia (21-01-2010), Nueva Zelanda (BOE 26-01-2010), Chile (BOE 09-02-2010), Perú (BOE 19-05-2010), Paraguay (BOE 21-06-2010), Islandia (BOE 16-12-2010), Bolivia (BOE 17-12-210), Cabo Verde (BOE 13-01-2011), Corea del Sur (BOE 06-07-2011) y Trinidad y Tobago (BOE 02-12-2011).

14 Se puede consultar el recorrido y debate parlamentario de ambas iniciativas en la web del Congreso de los Diputados (www. congreso.es)

15 Consejo de Ministros de 3 de abril de 2009. http://www.lamoncloa.gob.es/consejodeministros/referencias/paginas/2009/refc20090403. aspx/ (23-01-2019).

${ }^{16}$ El tratado suscrito con Nueva Zelanda recibe la denominación de "acuerdo», aunque realmente sería un canje de notas «diferido», ya que se remite a un posterior intercambio de documentos donde se especificarían las condiciones de ejercicio del derecho de sufragio municipal para sus nacionales que mutuamente se reconocen. 
Trinidad y Tobago, tan faltos de vínculos aparentes con España y con tan escaso peso poblacional ente la comunidad de residentes extranjeros (Santolaya, 2011: 25 y ss) ${ }^{17}$.

Sin embargo, a nuestro juicio, el prisma más interesante de análisis a los efectos que nos interesan en el presente artículo es el que afecta a la forma en que se ha aplicado el criterio de reciprocidad exigido por el art. 13.2 CE en este proceso de formalización de instrumentos internacionales de reconocimiento del derecho de sufragio municipal a los residentes extranjeros. Tal como se ha expuesto, existe un consenso consolidado que sostiene una interpretación flexible de la exigencia de la reciprocidad, que no implicaría una identidad total entre los requisitos de ejercicio del derecho reconocido en España y en el país contraparte. De esta manera, pueden producirse supuestos de reciprocidad "simétrica» (existe coincidencia en dichos requisitos) y «asimétrica» (hay disparidad en las condiciones de ejercicio). Analizamos los principales requisitos de ejercicio del sufragio local reconocido por estos tratados desde esta perspectiva:

- Reconocimiento de la dimensión activa y pasiva del sufragio. Ninguno de los instrumentos reconoce el sufragio pasivo municipal. Se podría plantear si el reconocimiento o no de la dimensión pasiva del sufragio cabe dentro de la flexibilidad interpretativa del criterio de reciprocidad, o si afecta a la «esencia» del mismo. Es decir, si es posible que España reconociera la opción de concurrir como candidata a las elecciones municipales a una persona extranjera residente nacional de un país que vetara ese derecho a los españoles, o por el contrario ello violentaría las bases de la exigencia del texto constitucional. A nuestro juicio la señalada flexibilidad daría cobertura a esta circunstancia, considerando que la exigencia de reciprocidad quedaría cumplimentada con el reconocimiento genérico para las personas nacionales españolas del derecho a participar en las elecciones municipales, aunque sea en unas condiciones más restrictivas que las previstas en el ordenamiento español (excluyendo el sufragio pasivo, p. ej.). Pero incluso en el caso de que se sostuviera la posición contraria, en algunos supuestos la restricción al sufragio activo por parte de España ha sido una decisión estrictamente política, ya que la contraparte sí reconoce en su ordenamiento jurídico el sufragio pasivo para los nacionales españoles. De esta manera, respecto al no reconocimiento del sufragio pasivo podemos distinguir:

- Tratados de «reciprocidad simétrica» con Bolivia, Chile, Colombia, Corea del Sur, Ecuador, Islandia, Nueva Zelanda y Trinidad y Tobago (en todos estos Estados no se reconoce el sufragio pasivo para residentes extranjeros en los comicios municipales) ${ }^{18}$.

- Tratados de «reciprocidad asimétrica» con Cabo Verde, Paraguay y Perú. En este grupo también hay que incluir a Noruega, ya que aunque cuando entró en vigor su instrumento internacional (1991) no se había producido todavía la reforma del art. 13.2 CE que abrió el sufragio pasivo local a los residentes extranjeros en España, a partir de la reforma podemos hablar de una «asimetría sobrevenida». Todos ellos reconocen, de forma plena o con restricciones, el sufragio pasivo municipal a los residentes extranjeros, incluyendo a los de nacionalidad española, por supuesto. Por lo tanto, los nacionales españoles tienen más derechos de participación política en estos países que sus nacionales en España por una decisión política, ya que hubiera sido totalmente factible haber incluido en estos tratados el reconocimiento recíproco del citado sufragio pasivo municipal.

- Plazo de residencia legal exigido. La exigencia de residencia legal es común en todos los países parte de estos tratados, existiendo diferentes plazos mínimos exigidos, y también «simetrías» y «asimetrías» en la reciprocidad en este requisito. Antes de analizar esta perspectiva, hay que destacar que ni el art. 13.2 CE, ni la LO 4/2000 (LOEX), ni la LO 5/1985 (LOREG) establecen ningún plazo mínimo para que los residentes extranjeros puedan ejercer el sufragio municipal en España. Es decir, que en sentido estricto en esta materia en todos los tratados habría una reciprocidad asimétrica, porque el resto de Estados sí que establecen un plazo exigible. Los 11 instrumentos internacionales suscritos en el periodo 2009-2011 determinan un plazo mínimo de residencia de 5 años, siendo posible que esta circunstancia se deba a que sea el más común entre los países contraparte y el que contemplan tratados de referencia en la materia como la Convención sobre la Participación de la

17 Se puede esgrimir que eran los países donde es factible cumplir las exigencias de reciprocidad (SANTOLAYA 2011: 32)

18 Los datos sobre la situación del reconocimiento del derecho de sufragio en el Derecho comparado han sido obtenidos básicamente de las siguientes fuentes: ALÁEZ (2010), ARCE (2012), IBÁÑEZ (2009), LUCAS et al. (2008), MOYA y VIÑAS (2010), SANTOLAYA y DÍAZ (2008) y páginas «web» oficiales de las principales instituciones políticas de cada uno de los Estados. 
REALA. Nueva Época - N.o 11, Abril-Septiembre 2019 - ISSN: 1989-8975 - DOI: 10.24965/reala.v0i11.10591 - [Págs. 139-155]

Análisis de los tratados internacionales para el reconocimiento del derecho de sufragio local a personas extranjeras residentes..

Carlos Arce Jiménez

Personas Extranjeras en la Vida Pública a Nivel Local (Consejo de Europa, 1992). Por lo expuesto, no existía impedimento normativo para que España hubiera adaptado cada uno de los tratados al periodo de residencia exigido por cada contraparte, en vez de establecer un requisito estándar para todos. La reiterada interpretación flexible de la reciprocidad igualmente facilitaría esta opción.

Teniendo en cuenta estas precisiones, y tomando como referencia el término de 5 años, respecto al plazo mínimo de residencia requerido habría reciprocidad:

- «Simétrica» con Chile, Colombia, Ecuador, Islandia y Trinidad y Tobago (5 años). Desde esta perspectiva, también hay simetría en el tratado con Noruega suscrito en 1990, que exige 3 años, que es el plazo contemplado en la legislación noruega para los residentes extranjeros que no sean nacionales de países nórdicos.

- «Asimétrica» con Bolivia y Perú (que exigen 2 años), Cabo Verde y Corea del Sur (3 años), Paraguay (necesaria la «radicación definitiva» del residente extranjero, que no implica plazo de residencia mínimo) y Nueva Zelanda (condición de «residente permanente», para la que tampoco es necesario un plazo concreto).

El resto de requisitos, como la inscripción en el padrón del municipio en el que se pretenda ejercer de forma efectiva su derecho de sufragio local y el «voto rogado», tienen una configuración diversa en cada uno de los países contraparte. Dado el carácter eminentemente administrativo de los mismos, las diferencias en este terreno son subsumibles sin dificultad en la perspectiva no restrictiva del criterio de reciprocidad. Una cuestión distinta es el impacto material sobre la participación real de los residentes extranjeros que tiene optar por unos requisitos administrativos u otros, especialmente el "voto rogado», cuestión a la que regresaremos en las próximas líneas.

Por último, aunque los instrumentos internacionales objeto de nuestro análisis se centraban en la participación política en el ámbito local, es pertinente indicar que algunos de los Estados contraparte reconocen a los extranjeros derechos políticos en ámbitos territoriales superiores al municipal, como es el caso de Chile, Ecuador y Nueva Zelanda. El ordenamiento español vigente restringe la intervención política de los residentes extranjeros al nivel local, aunque distintas voces en la doctrina sostienen la viabilidad y/o necesidad de realizar las modificaciones normativas precisas para avanzar en el reconocimiento del derecho de sufragio de los residentes extranjeros en España en elecciones autonómicas, estatales y europeas. Entre otros, Agudo (2016: 327-328), Arce (2012: 407 y ss), Durán y Martín, (2008: 166 y 167), Santolaya y Revenga (2007: 23) y Presno (2003: 97).

\section{VALORACIÓN DE LA INCIDENCIA PRÁCTICA DE LOS NUEVOS TRATADOS EN EL AVANCE DEL RECONOCIMIENTO DEL DERECHO DE SUFRAGIO MUNICIPAL DE LOS RESIDENTES EXTRANJEROS}

Tal como indicamos más arriba, es de justicia señalar que estos tratados representan un paso adelante en comparación con la primera fase que tuvo lugar entre finales de los años ochenta y principios de los noventa, en cuanto muestran una voluntad política más decidida a avanzar en este ámbito. Sin embargo, se puede cuestionar el resultado efectivo del proceso, tanto desde una perspectiva general como desde la específica que afecta a los 11 instrumentos internacionales concretos que son objeto de nuestro análisis.

Se evidencian de nuevo las graves dificultades que conlleva la «vía» de suscripción de tratados internacionales bajo el criterio de reciprocidad para la ampliación del derecho de sufragio de las personas extranjeras residentes España en el ámbito municipal (Naranjo, 2017: 98), debido a que:

- La exigencia de reciprocidad impide acceder al sufragio municipal a los residentes nacionales de países no democráticos y es susceptible de convertirse en una mera herramienta para los intereses de la política exterior española.

- Existen las descritas «asimetrías internas y externas» en varios de los tratados en vigor.

En lo que respecta a los nacionales de países sin tratados, se podría sostener que los Estados con los que se suscribieron los instrumentos vigentes eran los únicos con los que era factible cumplir las exigencias de reciprocidad (Santolaya 2011: 32). Es posible poner en cuestión una afirmación tan categórica, empezando por los cuatro países que se incluían en el plan inicial de suscripción de tratados del Estado español de 2009 con los que finalmente no se formalizaron. En los casos de Argentina y Uruguay, su exclusión se debió 
a una valoración subjetiva respecto a la no adecuación de los requisitos de ejercicio del derecho sufragio local por los residentes extranjeros en estos países al criterio de reciprocidad, no habiendo nada que de forma absoluta haga inviable la interpretación contraria. En lo que respecta a Burkina Faso y Venezuela, al no haberse siquiera completado la tramitación de sus respectivos canjes de notas, no se puede presumir de entrada que estos no encajarían con las exigencias de la reciprocidad. En la misma línea, no es descabellado pensar que obtuviera algún resultado positivo una búsqueda más exhaustiva de Estados cuya regulación del sufragio local podría configurarlos como «candidatos» para nuevos tratados desde la consabida interpretación más laxa de la exigencia de reciprocidad, así como siempre existe la posibilidad de que países que actualmente no reconocen derechos de participación política municipal a personas extranjeras lo hagan en un futuro próximo. A pesar de lo expuesto, entendemos que priorizar la vía legal sobre la convencional sería necesario para avanzar en el reconocimiento del derecho de sufragio local de los residentes extranjeros en España de una manera más ágil, sin perjuicio de que la exigencia de reciprocidad siga representando el principal obstáculo para una perspectiva «pro derechos» en esta materia.

Centrándonos en los Estados con los que España ha suscrito los tratados analizados ${ }^{19}$, las asimetrías existentes en el trato normativo a personas extranjeras en base a su origen nacional tienen dificultades de encaje con los requisitos dispuestos por la jurisprudencia constitucional para no vulnerar el principio de igualdad ${ }^{20}$ : desigualdad de supuestos de hecho, interdicción de la arbitrariedad, racionalidad y proporcionalidad. Permitiendo el art. 13.2 CE el reconocimiento de sufragio activo y pasivo local a residentes extranjeros sin pronunciamiento respecto a un plazo mínimo de residencia, respetando la exigencia reciprocidad en teoría no deberían existir diferencias por origen nacional. A pesar de ello, en la actualidad encontramos tres niveles de reconocimiento:

- Ciudadanos de la Unión Europea: Tienen reconocido sufragio activo y pasivo y no se le exige ningún periodo mínimo de residencia.

- Nacionales de Noruega: Sufragio activo y residencia en España de al menos 3 años.

- Nacionales del resto de países con los que España ha suscrito tratados: Sufragio activo y residencia mínima de 5 años.

Algunos autores afirman que estaría justificado el trato diferenciado a los nacionales de los Estados UE, por el hecho de ostentar la ciudadanía europea (Ibáñez, 2009: 62-63), posicionamiento que sin compartir$\mathrm{lo}^{21}$, admitimos que es sostenible por el hecho de existir una circunstancia objetiva que al menos permitiría defender que estamos ante supuestos de hecho diferentes.

Consideramos más cuestionable aún las diferencias entre residentes nacionales de terceros países con el derecho al sufragio local reconocido. Es inconsistente la argumentación de que las mismas son consecuencia de la aplicación del principio de reciprocidad, porque como hemos señalado en estas líneas existe un amplio consenso entre la doctrina -Esteban (2006), Moya (2010), Naranjo (2017), Pérez (2013) y Santolaya (2007)- y es opinión declarada del Consejo de Estado (Informe 24 de febrero de 2009: 353-354) que debe realizarse una interpretación flexible del requisito. A mayor abundamiento, incluso partiendo de una interpretación restrictiva de la reciprocidad no se podría justificar la existencia de "asimetrías» entre los distintos tratados analizados. En este sentido, no encajaría con la reciprocidad estricta que a los ciudadanos noruegos se les exija 3 años de residencia y a paraguayos, neozelandeses, bolivianos, peruanos, caboverdianos y coreanos 5. Efectivamente a los españoles residentes en Noruega se le exigen 3 años de residencia, pero en los otros países citados el periodo exigido oscila entre 0 y 3 años, por lo que desde una aplicación restrictiva de la reciprocidad se hubiera impuesto adaptar cada uno de los tratados al requisito temporal correspondiente. Siendo entonces evidente que la diferenciación no encuentra fundamento en la reciprocidad, se les podría como mínimo haber equiparado con los residentes noruegos en este requisito.

19 Junto a los ciudadanos europeos, por supuesto.

20 Entre otras, SSTC 216/1991, 253/2004 y 84/2008.

21 En el marco establecido por el art. 13.2 CE, el reconocimiento de los derechos de participación de estos residentes extranjeros en España se basa más en la existencia de un tratado internacional en esta materia bajo el criterio de la reciprocidad (Tratado de Maastricht) que por el «advenimiento» de la ciudadanía europea. Y desde un punto de vista material, la equiparación entre ciudadanos europeos y residentes de terceros países en el derecho de sufragio municipal no supone un cuestionamiento del contenido efectivo de la ciudadanía europea. Este instrumento político-jurídico otorga a sus titulares una tabla de derechos que superan ampliamente la participación electoral municipal: libertad profesional y derecho al trabajo en el espacio UE (art. 15.2 CDFUE), no discriminación por razón de nacionalidad (art. 21.2 CDFUE), sufragio activo y pasivo en las elecciones europeas (art. 39.1 CDFUE), libertad de circulación y residencia en la UE (art. 45 CDFUE), protección diplomática en terceros países (art. 46 CDFUE)... 
REALA. Nueva Época - N.o 11, Abril-Septiembre 2019 - ISSN: 1989-8975 - DOI: 10.24965/reala.v0i11.10591 - [Págs. 139-155]

Análisis de los tratados internacionales para el reconocimiento del derecho de sufragio local a personas extranjeras residentes..

Carlos Arce Jiménez

Para cerrar esta argumentación, indicar que existe jurisprudencia constitucional que avala la «asimetría externa», y por ende la reiterada flexibilidad en la interpretación del criterio de reciprocidad en el ámbito de las relaciones internacionales (SSTC 102/2000, 30/2006, 177/2006). Sin embargo, ninguna de estas sentencias aborda los requerimientos específicos que pudieran justificar casos de «asimetría interna» como los que nos ocupan. Por lo que, a nuestro juicio, ésta debe ser interpretada por los citados requisitos generales dispuestos por el Tribunal Constitucional para no vulnerar el principio de igualdad y siempre a la luz del principio de interpretación de la legalidad en el sentido más favorable a los derechos fundamentales ${ }^{22}$. Desde este punto de vista, no existiendo una desigualdad de supuestos de hecho ni una finalidad razonable en el trato normativo desigual analizado, debemos concluir que es una decisión estrictamente política incompatible con las condiciones mínimas para su encaje en el marco constitucional vigente,

Existe otra circunstancia clave que pone en cuestión la efectividad práctica del reconocimiento del de derecho de sufragio local a determinados residentes extranjeros en España, ya sea a través de los tratados bilaterales bajo el criterio de reciprocidad o de la ciudadanía europea. Nos referimos a la necesidad de inscribirse en el censo electoral a instancias de parte o «voto rogado» ${ }^{23}$. Para entender como un aparentemente inocuo requisito administrativo puede suponer un serio obstáculo para el ejercicio normalizado de un derecho fundamental es pertinente aludir al concepto de «estructura de oportunidades políticas» -EOP-, que se refiere tanto a las reglas formales vinculadas al contexto institucional como a los procesos informales que tienen lugar en la sociedad receptora y que pueden incidir sobre la integración -política- de los inmigrantes (Pérez-Nievas et al. 2014: 11). Dentro de la EOP, las reglas electorales aplicables a los residentes extranjeros juegan un papel muy relevante; a medida que son más restrictivas y/o conllevan una mayor carga burocrática desincentivan claramente la participación.

Por el contrario, algunos autores señalan que el reconocimiento formal del derecho de sufragio a los residentes extranjeros y la flexibilización de los requisitos formales para su ejercicio no conlleva una mejora automática de su integración política. En los países con mayor recorrido en la participación política de su población de origen inmigrante (especialmente los nórdicos), se han realizado estudios sociopolíticos que ponen de relieve una infrarrepresentación del colectivo constante en el tiempo (Pérez-Nievas et al. 2014: 10). Hay quien sostiene que esta circunstancia deriva de la falta de sentimiento de pertenencia de los residentes extranjeros al país de acogida, aunque por nuestra parte consideramos que las motivaciones se sitúan más en la existencia de una «estructura de oportunidades políticas» desequilibrada.

Partiendo de estas consideraciones generales, pasaremos a analizar brevemente la influencia de la exigencia del voto rogado en los altos niveles de abstención de las personas extranjeras que tienen reconocido el derecho de sufragio municipal en España.

Como punto de partida, debemos insistir en que desde un concepto de reciprocidad flexible no se puede entender que la inscripción en el Censo Electoral de Residentes Extranjeros (CERE) a instancia de parte sea una consecuencia derivada del requisito establecido por el art. 13.2 CE. Es decir, que incluso se establezca una exigencia de este tipo a las personas españolas que residen en los países con los que ha suscrito tratados para el reconocimiento mutuo del derecho de sufragio local, España no está obligada a excluir los residentes extranjeros de dichos Estados de la incorporación de oficio al censo electoral desde el Padrón municipal de la que disfrutan los votantes de nacionalidad española. En esta línea, en lo que respecta a los ciudadanos UE, la directiva que regula el derecho de sufragio municipal vinculado a la ciudadanía europea determina que

todos los ciudadanos de la Unión, tengan o no la nacionalidad de su Estado miembro de residencia, puedan ejercer en él en igualdad de condiciones su derecho de sufragio activo y pasivo en las elecciones municipales...los ciudadanos no nacionales no deben estar sujetos a condiciones especificas a menos que, excepcionalmente, pueda justificarse un trato diferente de los nacionales y de los no nacionales por circunstancias especiales que distingan a estos últimos de los primeros (Exposición de motivos de la Directiva 94/80/CE).

22 STC 105/2012, FJ7: El principio de interpretación de la legalidad en el sentido más favorable a los derechos fundamentales ha sido reconocido reiteradamente por este Tribunal, tanto en términos generales, como a propósito de los derechos de sufragio activo y pasivo (SSTC 76/1987, de 25 de mayo, FJ 2; 24/1990, de 15 de febrero, FF JJ 2 y 6; 26/1990, de 19 de febrero, FF JJ 4 y 9; 87/1999, de 25 de mayo, FJ 3; 146/1999, de 27 de julio, FJ 6; y 153/2003, de 17 de julio, FJ 7)

${ }^{23}$ Esta situación es compartida con las personas españolas residentes en el exterior, lo cual ha tenido un gran impacto negativo en los niveles de abstención electoral de este colectivo Un completo análisis sobre el derecho de sufragio de los nacionales españoles residentes en el extranjero en GARCÍA (2012) y MARCOS (2012). 
REALA. Nueva Época - N.o 11, Abril-Septiembre 2019 - ISSN: 1989-8975 - DOI: 10.24965/reala.v0i11.10591 - [Págs. 139-155]

Análisis de los tratados internacionales para el reconocimiento del derecho de sufragio local a personas extranjeras residentes..

Carlos Arce Jiménez

A nuestro juicio, no existe ninguna de las circunstancias excepcionales exigidas por la directiva para que los ciudadanos europeos que viven en España tengan un sistema de acceso al censo electoral más gravoso que el exigido para los nacionales españoles. De hecho, la LO 5/1985 (LOREG) no determina la obligación de que la inscripción en el CERE sea a instancia de parte. El voto rogado para personas residentes extranjeras se impone a través de normas de rango reglamentario, algunas de ellas de un escalafón normativo tan bajo como las resoluciones ${ }^{24}$.

Voces de la doctrina sostienen la necesidad de la inscripción a instancia de parte en el CERE. Hay quien considera que los residentes extranjeros suelen tener una movilidad geográfica superior a la media, por lo que el CERE tiene una mayor variabilidad que el censo de españoles residentes entre elecciones (Ortega 2011: 31), haciendo pertinente el alta específica para cada convocatoria para una mejor gestión de esos numerosos cambios. Otros autores valoran al voto rogado como una garantía de la voluntariedad del ejercicio del derecho de sufragio de los residentes extranjeros (Lozano 1991: 103 y ss), o en general afirman que son aceptables condiciones adicionales al tiempo de residencia siempre que superen un juicio de proporcionalidad y no sean, en sí mismas, discriminatorias (Santolaya 2011: 22). Con Naranjo rechazamos estas argumentaciones, ya que:

la exigencia de instancia de parte para la inscripción en el censo electoral, como la de renovación de dicha solicitud con motivo de cada proceso resultan injustificadas e innecesarias para fin atendible alguno. Esto hace que su imposición sea desproporcionada y dificulte su ejercicio «más allá de lo razonable» (STC 11/1981, F. J. 8), por lo que al tiempo que lesiona el derecho de sufragio activo de los extranjeros en las elecciones municipales, constituye una discriminación entre el ciudadano español y el extranjero en el ejercicio de tal derecho (Naranjo 2017: 118-119).

El procedimiento de inscripción en el CERE tiene algunas especificaciones diferentes para ciudadanos europeos y para residentes extranjeros de terceros países con tratado, pero los elementos fundamentales del mismo son comunes:

- La Oficina del Censo Electoral envía una comunicación a las personas extranjeras residentes con derecho al voto municipal (en el caso de los ciudadanos UE solo se remitirá a aquéllos a los que no se hubiera hecho en procedimientos anteriores).

- Se prevén campañas informativas institucionales sobre este procedimiento.

- Las personas requeridas deberán manifestar su voluntad de participación, en los ayuntamientos de los municipios en los que residan y también conforme a los procedimientos de administración electrónica que se establezcan. El plazo es muy reducido (45 días).

- La manifestación de voluntad debe renovarse en cada convocatoria electoral.

Este procedimiento ha sido frontalmente rechazado desde las comunidades de residentes extranjeros y por colectivos de la sociedad civil que trabajan en el ámbito de los Derechos Humanos y migraciones. Alegan falta de información a los potenciales votantes ${ }^{25}$, descoordinación entre las administraciones implicadas, escasez de plazo para cumplimentar los trámites de alta en el $\mathrm{CERE}^{26}$, ausencia de justificación en la obligación de renovar la voluntad de participar en cada elección...

Las deficiencias de la «vía convencional bilateral» para el reconocimiento del sufragio municipal en España los residentes extranjeros que hemos ido analizando a lo largo de estas líneas evidentemente tienen sus consecuencias negativas materiales:

24 Real Decreto 202/1995, de 10 de febrero, por el que se dispone la formación del censo electoral de extranjeros residentes en España para las elecciones municipales. Orden EHA/2264/2010, de 20 de julio, por la que se dictan normas e instrucciones técnicas para la formación del censo electoral de residentes en España que sean nacionales de países con Acuerdos para las elecciones municipales, modificada por la Orden ECC/1758/2014, de 23 de septiembre. Real Decreto 147/1999, de 29 de enero, de modificación del Real Decreto 157/1996, de 2 de febrero, por el que se dispone la actualización mensual del censo electoral y se regulan los datos necesarios para la inscripción en el mismo. Resolución de 7 de septiembre de 2010, de la Oficina del Censo Electoral, por la que se establecen los procedimientos y se aprueba el modelo de solicitud para la inscripción en el censo electoral para las elecciones municipales de los ciudadanos nacionales de países de la Unión Europea, modificada por la Resolución de la Oficina del Censo Electoral de 12 de abril de 2013.

25 Por las muy deficientes campañas institucionales sobre esta materia, a todas luces insuficientes en «cantidad y calidad». Ya con motivo de los comicios municipales del año 2011, los primeros en los que estaban en vigor los nuevos tratados bilaterales, lo pusieron de relieve los más de 50 colectivos sociales integrados en la plataforma "Tod@s iguales, tod@s ciudadan@s" https://www.apdha. org/la-desinformacion-y-la-burocracia-causan-la-baja-inscripcion-en-el-censo-electoral/ (23-01-2019)

26 Tuvo que ser ampliado en las elecciones municipales de 2011 y 2015. 
- Ya hemos señalado que deja fuera a importantes comunidades de residentes extranjeros en España al ser imposible o difícil cubrir la exigencia de reciprocidad con sus países de origen, o porque simplemente no hay voluntad política por parte del Estado español de suscribir tratados con los mismos. En este sentido es significativo que 6 de las 15 principales nacionalidades de residentes extranjeros en España no tengan reconocido el derecho de sufragio local, al no ser Estados miembro de la UE o no tener en vigor tratados bilaterales ${ }^{27}$.

- Igualmente hemos destacado que la exclusión del sufragio pasivo o el elevado plazo mínimo de residencia establecido en los tratados suscritos ( 5 años) también representan limitaciones relevantes en esta materia.

- Por último, pero no menos importante por su impacto práctico, está la cuestión del voto rogado. Como ya hemos descrito, el procedimiento del ejercicio del derecho de sufragio local de los residentes extranjeros que lo tienen reconocido implica el envío por parte del Gobierno español de unas comunicaciones a aquellas personas de este colectivo que conste que cumplan los requisitos exigidos por los respectivos tratados (nacionalidad, residencia legal, plazo mínimo de residencia...), para que posteriormente procedan a darse de alta en el CERE. El nivel de participación electoral real en este ámbito se puede medir comparando el número de comunicaciones enviadas y los electores efectivamente inscritos. En la siguiente tabla vemos los datos referentes a los comicios municipales de 2011 y $2015^{28}$ :

PARTICIPACIÓN DE RESIDENTES EXTRANJEROS NO UE CON DERECHO AL VOTO EN LAS ELECCIONES MUNICIPALES DE 2011 Y 2015

\begin{tabular}{lcccccc}
\hline \multicolumn{1}{c}{ País } & $\begin{array}{c}\text { Comunicaciones } \\
\text { enviadas 2011 }\end{array}$ & $\begin{array}{c}\text { Electores } \\
\text { inscritos } \\
\mathbf{2 0 1 1}\end{array}$ & $\begin{array}{c}\text { \% } \\
\text { inscritos } \\
\mathbf{2 0 1 1}\end{array}$ & $\begin{array}{c}\text { Comunicaciones } \\
\text { enviadas 2015 }\end{array}$ & $\begin{array}{c}\text { Electores } \\
\text { inscritos } \\
\mathbf{2 0 1 5}\end{array}$ & $\begin{array}{c}\text { \% } \\
\text { inscritos } \\
\mathbf{2 0 1 5}\end{array}$ \\
\hline Bolivia & 27.502 & 4.209 & $15,3 \%$ & 47.474 & 3.952 & $8,32 \%$ \\
\hline Cabo Verde & 0 & 22 & - & 1.493 & 112 & $7,5 \%$ \\
\hline Chile & 10.078 & 1.131 & $11,22 \%$ & 11.499 & 999 & $8,68 \%$ \\
\hline Colombia & 95.192 & 11.195 & $11,76 \%$ & 88.685 & 5.763 & $6,5 \%$ \\
\hline Corea del Sur & - & - & - & 1.158 & 125 & $10,79 \%$ \\
\hline Ecuador & 168.639 & 22.213 & $13.17 \%$ & 125.022 & 6.485 & $5,19 \%$ \\
\hline Islandia & 152 & 24 & $15,79 \%$ & 370 & 35 & $9,46 \%$ \\
\hline Noruega & 6.027 & 790 & $13,10 \%$ & 8.792 & 854 & $9,71 \%$ \\
\hline Nueva Zelanda & 148 & 31 & $20,95 \%$ & 194 & 28 & $14,43 \%$ \\
\hline Paraguay & 4.305 & 574 & $13,33 \%$ & 15.172 & 1.300 & $8,57 \%$ \\
\hline Perú & 38.244 & 5.365 & $14,03 \%$ & 42.722 & 3.110 & $7,28 \%$ \\
\hline Trinidad y Tobago & - & - & - & 16 & $22 \%$ & $12,5 \%$ \\
\hline \multicolumn{1}{c}{ TOTAL } & 350.287 & 45.554 & $13 \%$ & 342.597 & 22.765 & $6,64 \%$ \\
\hline
\end{tabular}

Elaboración propia (Fuente: Instituto Nacional de Estadística).

Los porcentajes de participación efectiva son llamativamente bajos, y lejos de mejorar, en los comicios de 2015 se produjo una drástica reducción respecto a los del 2011. Ya indicamos más arriba que se puede

27 Marroquíes (1. ${ }^{a}$ comunidad extranjera), chinos $\left(5 .^{a}\right)$, ucranianos, $\left(12 .^{a}\right)$ venezolanos $\left(13 .^{a}\right)$, argentinos $\left(14 . .^{a}\right)$ y rusos $\left(15 .{ }^{a}\right)$, no tienen reconocido el derecho de sufragio local en España https://www.ine.es/prensa/cp_e2018_p.pdf (23-01-2019)

${ }^{28}$ Hay que destacar que no es obligatorio el remitir comunicaciones a todos los ciudadanos europeos en cada uno de los comicios, por lo que no es posible disponer de datos completos sobre ellos. Por esta circunstancia hacemos referencia exclusivamente a los datos de participación de los electores de países no pertenecientes a la UE con acuerdo en materia electoral local con España. 
REALA. Nueva Época - N.o 11, Abril-Septiembre 2019 - ISSN: 1989-8975 - DOI: 10.24965/reala.v0i11.10591 - [Págs. 139-155]

Análisis de los tratados internacionales para el reconocimiento del derecho de sufragio local a personas extranjeras residentes..

Carlos Arce Jiménez

argumentar que esta situación se debe al escaso sentido de pertenencia a la comunidad sociopolítica española de las personas residentes extranjeras, pero a nuestro juicio el voto rogado es un factor decisivo de fomento de la abstención, y representa un ataque al principio de igualdad material comparativamente con los nacionales españoles que carece de justificación objetiva y afecta gravemente al contenido sustantivo de los derechos de participación política de este colectivo.

\section{CONCLUSIONES: PROPUESTAS DE MEDIDAS POLÍTICO-JURÍDICAS PARA AVANZAR EN LA UNIVERSALIZACIÓN DEL DERECHO DE SUFRAGIO A NIVEL LOCAL}

Por lo expuesto en los apartados anteriores, podemos calificar en general de fracaso la vía convencional bajo el criterio de reciprocidad aplicada hasta ahora como estrategia para impulsar el reconocimiento material del ejercicio de los derechos políticos por parte de los residentes extranjeros en España en el ámbito municipal. En concreto sostenemos que:

- La suscripción de tratados internacionales bajo el criterio de reciprocidad es un instrumento poco ágil que puede retrasar ostensiblemente el ejercicio efectivo de los derechos políticos.

- Perpetúa un «sistema de castas de ciudadanía» desde la perspectiva de la participación política.

- Es susceptible de ser utilizado más como una herramienta de la política exterior española que como un reconocimiento de derechos ciudadanos.

- Se ciñe exclusivamente a la participación en la vida política municipal, cerrando la posibilidad de reconocer derechos electorales en los ámbitos autonómico y estatal (Arce 2012: 397).

A nuestro juicio existen algunas posibles reformas en esta línea dentro del actual marco constitucional que supondrían avances en esta materia, aunque sería imprescindible afrontar una reforma de la Constitución de 1978 para conseguir el objetivo deseado en toda su dimensión.

\section{Posibles reformas dentro del marco constitucional vigente (respetando la exigencia de reciprocidad)}

- Supresión de la «reciprocidad asimétrica externa». Sería la medida más conservadora, que consistiría en establecer el principio de las «condiciones de ejercicio más favorables» cuando se formalicen tratados internacionales bajo el criterio de reciprocidad. Por lo tanto, si en el Estado con el que se suscribe el tratado se reconoce el sufragio pasivo municipal a los españoles, sea obligatorio que a sus nacionales también se les reconozca en España, o habría que imponer el plazo de residencia mínimo exigido menos extenso, p. ej.

- Supresión de la «reciprocidad asimétrica interna». Siguiendo el principio de la prevalencia de las "condiciones de ejercicio más favorables» y con la consolidada interpretación flexible de la reciprocidad, todos los residentes extranjeros con el derecho de sufragio local reconocido deben tener los mismos requisitos para su ejercicio, siendo aplicables las más ventajosas contempladas en los instrumentos internacionales formalizados. De esta manera las condiciones exigidas a los residentes extranjeros de que se trate para ejercer el derecho de sufragio local podrían ser modificadas «a mejor» en el momento que entre en vigor un tratado con unos requisitos menos restrictivos.

- Priorizar la vía legal sobre la convencional para reconocer el derecho de sufragio municipal. Consistiría en utilizar la posibilidad contemplada en el art. 13.2 CE de reconocer el derecho de sufragio municipal bajo el criterio de reciprocidad por ley y no mediante tratados internacionales. A través de una modificación de la LO 5/1985 (LOREG) se establecería un reconocimiento general del derecho de sufragio municipal con unos requisitos de residencia no muy exigentes a todas las personas extranjeras residentes en España cuyo país de origen haga lo propio con los nacionales españoles, aunque sea con unas condiciones de ejercicio diferentes (Presno 2011: 103) ${ }^{29}$. Sería el Gobierno de España el competente para confirmar que en el país de origen de la persona extranjera de que se trate se reconoce los mismos derechos a los nacionales españoles. Para esta

29 Nos reafirmamos en el convencimiento de que la flexibilidad del criterio de reciprocidad puede alcanzar a reconocer el sufragio pasivo a residentes extranjeros aunque las personas españolas solo tengan habilitado el activo en su país de origen. 
comprobación debería elaborar y actualizar el Ministerio de Asuntos Exteriores, Unión Europea y Cooperación en colaboración con la Oficina del Censo Electoral un listado de países con los que se cumplen los requisitos de la reciprocidad a cuyos nacionales que residan en España se les reconocería automáticamente estos derechos. También debería estar abierta la posibilidad de que cualquier residente extranjero en España cuyo país de origen no está incluido en el listado, y que considere que éste reconoce a los españoles el derecho de sufragio local, inste al Gobierno español a incorporar al Estado de que se trate en esa relación de países. Este reconocimiento legal debería agotar las posibilidades del ordenamiento jurídico vigente: reconocimiento tanto del derecho de sufragio activo como el pasivo y no exigir plazo de residencia mínimo, bastando con ser titular del correspondiente permiso de residencia, algo que ya ocurre con las personas que ostentan la ciudadanía europea.

\section{Reformas que superan el marco constitucional vigente}

- Supresión de la exigencia de reciprocidad para el reconocimiento del derecho de sufragio local de los residentes extranjeros. Ello conllevaría la modificación del art. 13.2 CE, eliminando la expresión "atendiendo a criterios de reciprocidad» del mismo. No existiendo la exigencia de la reciprocidad, en cierto sentido la vía convencional de reconocimiento del derecho de sufragio carece de virtualidad práctica, ya que el Estado español podría acometer el reconocimiento del mismo de forma unilateral a través de su Derecho interno. Sin embargo, sin negar la consistencia del argumento anterior, la suscripción de tratados internacionales que en el ámbito supranacional apuesten por la universalización de la participación política supone una reafirmación de la voluntad política de avanzar hacia la consolidación de una verdadera ciudadanía inclusiva ${ }^{30}$. Esos compromisos internacionales también impedirían «regresiones» normativas en este ámbito que serían posibles por la exclusiva decisión individual del Estado español sobre su ordenamiento interno en la ausencia de dichos instrumentos. Por lo expuesto, consideramos pertinente mantener la «vía convencional» en una hipotética nueva redacción del art. 13.2 CE. Hay que destacar que para esta reforma se tendría que utilizar el procedimiento ordinario (art. $167 \mathrm{CE}$ ), por lo que no podría esgrimirse la complejidad disuasoria que afecta al agravado del art. $168 \mathrm{CE}$ que mantiene paralizadas otras reformas constitucionales sobre las que incluso existe un amplio consenso político que se acerca a la unanimidad ${ }^{31}$.

- La residencia legal como único requisito para el ejercicio de los derechos electorales de las personas extranjeras en plenitud en el ámbito municipal. Una vez suprimido el criterio de reciprocidad, habría que acometer las reformas pertinentes en el ordenamiento infraconstitucional para adaptarlo al nuevo marco de titularidad y ejercicio de los derechos de sufragio de las personas extranjeras a nivel municipal. Se debería generalizar el régimen que disfrutan actualmente los ciudadanos europeos a todos los residentes extranjeros en España, es decir, reconocimiento tanto del derecho de sufragio activo y pasivo y la residencia legal como único requisito exigible. A nuestro juicio no existen elementos jurídico-políticos que justifiquen la imposición de un plazo mínimo de residencia a los nacionales de terceros países y no a los ciudadanos europeos, por los argumentos expuestos anteriormente al abogar por la supresión de la «reciprocidad asimétrica interna». De esta manera, básicamente habría que acometer la reforma de los arts. 6, 176 y 177 de la LO 5/1985 (LOREG)

- No compartimos la afirmación de Santolaya respecto a que el marco constitucional actual no permite una interpretación expansiva del concepto de ciudadanía que permita superar la vinculación entre nacionalidad y la plenitud de la titularidad y ejercicio de los derechos fundamentales (Santolaya 2011: 18). Ya hemos sostenido en otras ocasiones que es factible una renovación inclusiva de conceptos como ciudadanía y pueblo ${ }^{32}$ que ofrezca una respuesta adecuada en materia de titularidad

30 Un ejemplo en este sentido sería el Convenio Europeo sobre la participación de los extranjeros en la vida pública local (Consejo de Europa, 1992).

31 Entre ellas sin duda se encuentra la supresión de la desigualdad por razones de género que establece el art. 57.1 CE en la sucesión de la Jefatura del Estado.

${ }_{32}$ Miguel Ángel Presno propone definir pueblo español como personas sometidas al ordenamiento jurídico español con independencia de su nacionalidad (Presno 2003, 97). 
REALA. Nueva Época - N.o 11, Abril-Septiembre 2019 - ISSN: 1989-8975 - DOI: 10.24965/reala.v0i11.10591 - [Págs. 139-155]

Análisis de los tratados internacionales para el reconocimiento del derecho de sufragio local a personas extranjeras residentes..

Carlos Arce Jiménez

y ejercicio de derechos fundamentales a las nuevas sociedades diversas y transnacionales fruto de los flujos migratorios vinculados a la globalización. En esta línea consideramos factible ampliar los derechos de participación política representativa de los residentes extranjeros al ámbito autonómico (Agudo 2016: 327-328) y al estatal ${ }^{33}$.

\section{REFERENCIAS BIBLIOGRÁFICAS}

AGUDO ZAMORA, M. (2016): "La participación política de los extranjeros residentes", en Revista Europea de Derechos Fundamentales, núm. 27, págs. 309-328.

ALÁEZ DEL CORRAL, B. (2010): "Ciudadanía democrática, multiculturalismo e inmigración”, en GARCÍA, F. J. y ALBERTI, E. (coords.): 30 años de Constitución. Valencia: Tirant lo Blanch.

ARCE JIMÉNEZ, C. (2012): Los derechos políticos de los residentes extranjeros. La ciudadanía inclusiva. Sevilla: Defensor del Pueblo Andaluz.

ARCE JIMÉNEZ, C. (2015): “Ciudadanía y derechos políticos de los residentes extranjeros en la Unión Europea”, en CORTÉS, A. y DÍAZ, P. (coords.): Ciudadanía temas y debates, págs. 71-101. Santiago de Chile: Centro de Estudios Bicentenario.

ARCE JIMÉNEZ, C. (2018): "Derecho de sufragio, Administración y principio de igualdad”, en Revista Estudios de Deusto, vol. 66, núm. 2. DOI: http://dx.doi.org/10.18543/ed-66(2)-2018pp249-280.

DURÁN MUÑOZ, R. y MARTÍN MARTÍNEZ, M. (2008): La integración política de los inmigrantes. La vía del sufragio. Granada: Comares.

ESTEBAN DE LA ROSA, F. (2006): "Artículo 6. Participación pública”, en ESPLUGUES, C. (coord.): Comentarios a la ley de extranjería, págs. 142-178. Valencia: Tirant lo Blanch.

GARCÍA MAHAMUT, R. (2012): "La reforma electoral (LO 2/2011) y el voto de los españoles en el exterior (CERA). La inefectividad del derecho de sufragio de los españoles en el exterior. Una necesaria revisión”, en UNED. Teoría y Realidad Constitucional, núm. 30, págs. 259-289. DOI: https://doi.org/10.5944/trc.30.2012.7007.

IBÁÑEZ MACÍAS, A. (2009): El derecho de sufragio de los extranjeros. Cuadernos "Bartolomé de las Casas". Madrid: Dykinson.

LOZANO GARCÍA, J. L. (1991): Derecho de sufragio de los extranjeros en las elecciones locales. Memoria monográfica del curso selectivo de formación de secretarios de Embajada (1990-1991). Madrid: Escuela Diplomática.

LUCAS MARTÍN, J. DE, y otros (2008): Los derechos de participación de los extranjeros como elemento de integración de los inmigrantes. Informes Economía y Sociedad. Bilbao: Fundación BBVA.

MARCOS DEL CANO, A. M. (2012): "Los derechos de los españoles residentes en el exterior: especial referencia a los derechos de participación”, en Revista Derechos y Libertades, núm. 27, págs. 103-139.

MOYA MALAPEIRA, D., VIÑAS FERRER, A. (eds.) (2010): Sufragio y participación política de los extranjeros extracomunitarios en Europa. Barcelona: Fundación Carles $\mathrm{Pi}$ i Sunyer.

${ }^{33}$ En este ámbito entran en juego dos de los criterios de interpretación de las normas del art. 3 Código Civil: indagar en la finalidad del legislador y valorar el contexto histórico en el que se aprobó la norma y en el que debe ser aplicada. Defendemos que en los 40 años de vigencia de la CE 1978 se han producido modificaciones normativas que, si se hubiera tenido en cuenta la voluntad del legislador en la realidad sociopolítica de su tiempo, hubieran carecido de cobertura constitucional. Ha sido el factor corrector de la interpretación del contexto histórico en el que debe ser aplicada la norma la que ha «salvado» la constitucionalidad. De esta manera la STC 137/2000 consideró que el derecho a la igualdad formal reconocido en el art. $14 \mathrm{CE}$ es un derecho fundamental en el que los extranjeros son titulares del mismo en las mismas condiciones que los españoles, no considerando un obstáculo que este precepto establezca como titulares del derecho a los españoles, sin necesidad de afrontar su reforma. También es significativo que el derecho de petición reconocido por el art.29 CE a los españoles, fuera reconocido por el art. 1 LO 4/2001 a toda persona natural o jurídica, prescindiendo de la nacionalidad... Esta norma no fue objeto de recurso de inconstitucionalidad ni se suscitó un debate respecto a la necesidad de reformar el art. 29 CE. Por supuesto que es imprescindible traer a colación a estos efectos la STC 198/2012 sobre la ampliación del matrimonio a personas del mismo sexo.

No nos cabe duda de que la voluntad del constituyente al utilizar el concepto «pueblo español» en el art. 1.2 CE era reservar la soberanía a los nacionales españoles. No cabía otra interpretación en el contexto del año 1978. Ahora bien, lo anterior no obsta para que atendiendo a la situación social, política y jurídica del siglo XXI en ese pueblo español titular de la soberanía se puedan incluir a ciudadanos miembros efectivos de la comunidad política que no ostenten la nacionalidad española. Partiendo de esta base, sería posible afrontar las reformas normativas precisas para abrir la participación de los residentes extranjeros a nivel autonómico y estatal sin que fuera necesario modificar el art. 1.2 CE. También existe la posibilidad de interpretar de una forma extensiva el concepto "ciudadano» del art. 23.1 CE, de manera que puedan entenderse incluidos también a los residentes extranjeros. A nuestro juicio el legislador constituyente pensó exclusivamente en los nacionales españoles al señalar como titulares de los derechos políticos a los «ciudadanos», pero que en el contexto actual es factible abogar por un concepto de ciudadanía que incluya a los extranjeros. De hecho, con la consolidación de la ciudadanía europea podríamos afirmar que esa posibilidad ya tiene una virtualidad jurídica práctica. (Arce 2012, 409 y 410). Además, no faltan ejemplos en el Derecho comparado de reconocimiento de derechos de participación política a extranjeros en el nivel estatal: Chile, Ecuador, Irlanda, Nueva Zelanda o Reino Unido. 
NARANJO DE LA CRUZ, R. (2017): "Elecciones municipales y derecho al voto de los extranjeros no comunitarios: estado de la cuestión y propuestas de reforma", en Revista de Derecho Político, núm. 100, págs. 81-122. DOI: https://doi.org/10.5944/rdp.100.2017.20684.

ONU (División de Población del Departamento de Asuntos Económicos y Sociales de Naciones) (2016): International

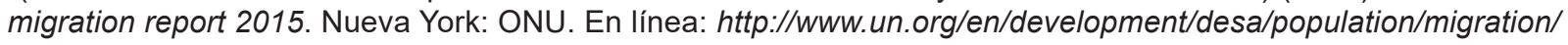
publications/migrationreport/docs/MigrationReport2015.pdf.

ORTEGA GIMÉNEZ, A. (2011): El derecho al voto de los ciudadanos extracomunitarios en las próximas elecciones municipales españolas de 2011. Madrid: Fundación Alternativas.

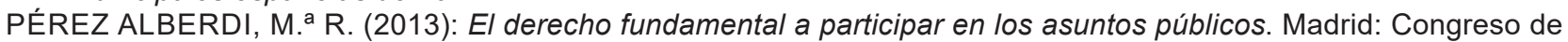
los Diputados.

PEREZ-NIEVAS, S., VINTILA, C. D., MORALES, L. y PARADÉS, M. (2014): "La representación política de los inmigrantes en elecciones municipales. Un análisis empírico", en CSIC Opiniones y actitudes, núm. 72.

PRESNO LINERA, M. A. (2003): El derecho de voto. Madrid: Tecnos.

PRESNO LINERA, M. A. (2011): "La reforma del derecho de voto en España", en Revista de Justicia Electoral, vol. 1, núm. 8, págs. 81-117.

SANTOLAYA MACHETTI, P. y REVENGA SÁNCHEZ, M. (2007): Nacionalidad, extranjería y derecho de sufragio. Madrid: Centro de Estudios Políticos y Constitucionales.

SANTOLAYA MACHETTI, P. y DÍAZ CREGO, M. (2008): El sufragio de los extranjeros. Un estudio de Derecho comparado. Madrid: Centro de Estudios Políticos y Constitucionales.

SANTOLAYA MACHETTI, P. (2011): "Los acuerdos sobre voto en las elecciones municipales en la IX Legislatura", en MATÍA PORTILLA, F. J. (coord.): Pluralidad de ciudadanías, nuevos derechos y participación democrática, págs. 35-58. Madrid: Centro de Estudios Constitucionales. 